\title{
TAXAS DE DESMATAMENTO E PRODUÇÃO AGROPECUÁRIA EM GOIÁS - 2003 a 2007
}

\author{
Msc. Elaine Barbosa da Silva \\ Doutoranda em Geografia da Universidade Federal de Goiás \\ Lab. de Processamento de Imagens e Geoprocessamento, Cx. Postal 131 - CEP 74001-970, Goiânia (GO) - Brasil \\ Tel: (55 62) 3521.1096 - elaine@posgrad.ufg.br \\ Prof. Dr. Laerte Guimarães Ferreira Júnior \\ laerte@iesa.ufg.br
}

\begin{abstract}
RESUMO
Neste trabalho avalia-se o uso de taxas de desmatamento para uma melhor compreensão do processo de ocupação e uso da terra no bioma Cerrado. Para tal, foram analisadas as taxas de desmatamento para os municípios do estado de Goiás referentes ao período de 2003 a 2007, as quais foram correlacionadas com a distribuição espacial da produção agrícola no estado. Este estudo mostrou que as taxas de desmatamentos mantêm estreita correlação com a distribuição espacial das principais commodities agrícolas. Porém, os resultados também sugerem cautela quanto ao uso de taxas para a previsão de cenários futuros, visto que estes são, geralmente, baseados em taxas estáticas, independentemente das significativas variações temporais e espaciais observadas e da interveniência de fatores políticos e sócio-econômicos.
\end{abstract}

Palavras-chave: Cerrado goiano. taxa de desmatamento. fronteira agropecuária.

\begin{abstract}
In this work we evaluated the use of deforestation rates for a better assessment and understanding regarding land use and occupation in the Cerrado biome. In particular, we analysed deforestation rates for the state of Goiás, on a municipality basis, for the 2003 - 2007 period, which were correlated to the respective agricultural spatial distribution. This study demonstrated that deforestation rates are closely related to the spatial distribution of major agricultural commodities. Nevertheless, our results also suggest caution regarding the use of these rates for predictive scenarios, which are often based on single figures, in spite the fact that rates are subject to significant spatial and temporal variations, mainly due to the influence of political and socioeconomic factors.
\end{abstract}

Key words: Cerrado. deforestation rate. agricultural frontier.

\section{RÉSUMÉ}

Sur cet article, nous évaluons l'utilisation des taux de déforestation pour une meilleure comprehension du procès de ocupation et l'utilisation des terres dans le Cerrado. À cette fin, nous avons analysé si les taux de déforestation pour les municipalités de Goiás dans le période 2003 a 2007, qui ont été corrélées avec la distribution spatiale de la production agricole dans l'État. Cette étude a montré que les taux de déforestation mainteint une corrélation étroite avec la distribution spatiale des principaux produits agricoles. Touefois, les résultats suggèrent prudence quant à l'utilisation de taux pour la prévision des scénarios futurs, puisque elles sont généralement basée en taux statique, indépendamment des significatives variations temporelles et spatiales observée et intervenant de facteurs politiques et socio-économiques.

Palabras-clave: Cerrado goiano. taux de déforestation. frontière agricole.

\section{INTRODUÇÃO}

O estado de Goiás, localizado na área nuclear do bioma Cerrado, é a unidade da federação com maior inserção nos limites fisiográficos deste bioma. Nas últimas décadas, o estado passou por um intenso processo de ocupação, em função da expansão agropecuária, a qual resultou na conversão de aproximadamente $63 \%$ de sua vegetação natural. É, portanto, uma das áreas do Cerrado com maior déficit de remanescentes (SANO et al., 2008, p. 93). A conversão acelerada do bioma levou Myers et al. (2000) e a ONG Conservação Internacional (2005, p. 3 ) a considerarem o bioma como um dos hotspots mundiais, i.e., uma área de alto endemismo de biodiversidade e elevado estágio de degradação. 
Apesar de tamanha devastação, a fronteira agrícola continua em expansão, sendo que a crescente demanda por biocombustíveis encontra em Goiás um ambiente favorável, no caso para o cultivo da cana-de-açúcar (RIBEIRO, 2008, p. 489). Por outro lado, as ações e estudos direcionados à preservação do bioma Cerrado em Goiás ainda são poucos e recentes, destacando-se o monitoramento do desmatamento realizado pelo Sistema Integrado de Alerta de Desmatamentos para o Cerrado (SIAD) (FERREIRA et al., 2007, p. 49; ROCHA et al., 2009, p. 2.986) e o mapeamento da cobertura vegetal realizado no âmbito do Projeto de Identificação de Áreas Prioritárias para Conservação da Biodiversidade no Estado de Goiás (PDIAP) (SANO et al., 2008, p. 91). Recentemente, no ano de 2008, o Instituto Brasileiro de Meio Ambiente e Recursos Hídricos (IBAMA) lançou o Projeto Monitoramento do Desmatamento dos Biomas Brasileiros por Satélite (PMBBS), iniciado justamente pelo bioma Cerrado (BRASIL, 2009).

Ao se tratar de desmatamento, é comum utilizar-se de taxas anuais para referir-se à problemática e, ainda, para fazer previsão de cenários futuros da conversão da vegetação. Como exemplo desta prática, destaca-se o estudo realizado por Machado et al. (2004, p. 6), que, com base nos levantamentos feitos por Dias (1994, p. 621) e por Mantovani e Pereira (1998, p. 1.459), estimaram uma taxa de desmatamento para o período de 1985 a 1993 de 1,5\% ao ano, sendo a criação de gado apontada como a principal causa do desmatamento. Posteriormente, os mesmos autores estimaram uma taxa para os anos de 1993 a 2002 de $0,67 \%$ ao ano, período que corresponde à intensificação do plantio de soja no país. Com base nestas duas taxas, Machado et al. (2004, p. 7) derivaram uma taxa média de $1,1 \%$ ao ano, a partir de 2002, correspondendo a uma perda de 2,2 milhões de hectares do Cerrado anualmente, o que levaria a um esgotamento dos remanescentes de vegetação do bioma Cerrado até o ano de 2030 (MACHADO et al., 2004, p. 8).

Uma dificuldade inerente ao uso de taxas de desmatamento é a generalização destas para o bioma ou para as unidades federativas. Ao atribuir-se um valor único para um mesmo espaço, desconsidera-se, com prejuízo para as próprias ações de preservação, que o processo de ocupação não ocorre de forma homogênea e que as causas do desmatamento variam de forma significativa.

Em fato, e ainda que uma taxa anual de desmatamento seja uma boa ferramenta para a compreensão do processo de desmatamento em curso, ela configura-se como uma forma generalizada de se tratar o problema, tendo em vista que as taxas raramente se mantêm constantes e em suas composições não são considerados os fatores socioeconômicos envolvidos diretamente no processo de conversão de vegetação. Assim, podem induzir a prognósticos equivocados. Diante desta problemática, pretende-se, neste trabalho, avaliar o uso de taxas de desmatamento como ferramenta para a compreensão da conversão atual da vegetação, bem como a possibilidade de indicarem tendências e cenários de ocupação do Cerrado goiano, a médio e longo prazo.

\section{MATERIAL E MÉTODOS}

Para a elaboração de taxas de desmatamento são necessários dois elementos: o quantitativo de vegetação (i.e, mapa de remanescentes) e o dado de desmatamento (i.e., mapa indicativo de conversões). O quantitativo de remanescentes teve por base o mapeamento da cobertura e uso da terra no estado de Goiás, à escala de 1:250.000, realizado no âmbito do PDIAP a partir da segmentação, classificação e interpretação visual de imagens Landsat ETM obtidas em 2002 (SANO et al., 2008, p. 93). Assim, adotou-se 2003 como tempo inicial (Ti) (figura1).

Quanto à escolha do dado de desmatamento, que também delimita o tempo final ( $\mathrm{Tf}$ ) do presente estudo (ano de 2007), foram utilizados os dados de alertas de desmatamentos gerados pelo SIAD, em razão de serem os únicos dados existentes e disponíveis para o estado de Goiás no período de realização da presente pesquisa (ROCHA et al., 2009, p. 2.988). Optou-se pelo recorte municipal para evitar a generalização para todo o estado. 
Com vistas a se entender a relação destas taxas com a produção agropecuária, também foram espacializados os principais produtos agropecuários produzidos em Goiás no período de 2003 a 2007, registrados pelo Instituto de Brasileiro de Geografia e Estatística (IBGE).

Basicamente, o processo de geração de taxas ocorreu em três etapas principais. Em um primeiro momento foram compiladas as delimitações municipais do estado de Goiás, disponibilizadas pelo IBGE, a base de dados de vegetação remanescente, disponibilizada através do Sistema de Estatística e Informação Geográfica (SIEG) (MOREIRA; FERREIRA, 2008) e os dados dos alertas de desmatamento gerados pelo SIAD, disponibilizados pelo Laboratório de Processamento de Imagens e Geoprocessamento do Instituto de Estudos Sócio-Ambientais da Universidade Federal de Goiás (LAPIG / IESA / UFG - acesse: www.lapig.iesa.ufg.br).

Em uma segunda etapa, estas bases de dados foram manipuladas em um sistema de informações geográficas (plataforma ArcGIS), com vistas à organização e espacialização dos dados conforme a divisão municipal e geração das taxas de desmatamento para o período de 2003 a 2007 (figura 2).

As taxas de desmatamento foram geradas de acordo com a fórmula abaixo [1], onde: $\mathrm{T}=$ Taxas de desmatamento; $\mathrm{A}=$ Alertas de desmatamento (SIAD) e $\mathrm{R}=$ Área dos remanescentes (ha) (PDIAP). Para os períodos interanuais (2003 a 2004; 2004 a 2005; 2005 a 2006; e 2006 a 2007), utilizou-se a mesma metodologia, sendo que, a cada período, foi refeita a contagem dos remanescentes (i.e. remanescentes PDIAP menos alertas acumulados).

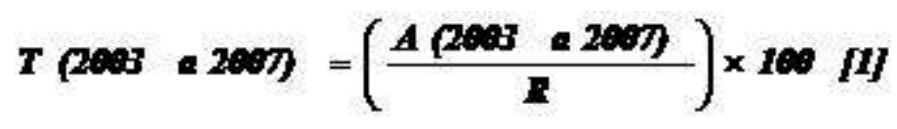

$\mathrm{Na}$ terceira etapa, foram espacializados os quantitativos dos principais produtos da agropecuária goiana - arroz, milho, feijão, soja, sorgo, algodão, cana e bovinos -, de acordo com os censos agropecuários elaborados pelo IBGE, para o período de 2003 a 2007. Esses dados foram adquiridos junto ao Sistema Estadual de Estatística e Informações Geográficas de Goiás (SIEG) e organizados e espacializados através da plataforma ArcGIS 9.3.

\section{RESULTADOS E DISCUSSÕES}

As taxas de desmatamento geradas para os municípios goianos, relativas ao período de 2003 a 2007 , foram, em média, de $1,1 \%$, ainda que variações de $0,01 \%$ a $5,37 \%$ tenham sido observadas (figura 3).

A espacialização destas taxas (figura 3) indica uma concentração de desmatamentos, no período em estudo, nas regiões Norte, Nordeste (corredor Paranã-Pireneus) e Noroeste de Goiás (Alto Araguaia). No Sudoeste e Sudeste as taxas de desmatamentos são baixas, enquanto que na região Sul as taxas são praticamente inexistentes.

Nas tabelas 1 e 2 apresentam-se os municípios responsáveis por 75\% dos desmatamentos ocorridos em cada período interanual (i.e., 2003 a 2004; 2004 a 2005; 2005 a 2006; e 2006 a 2007). As tabelas citadas mostram que apenas 14 municípios (em negrito) apresentaram reincidência em pelo menos dois dos quatro períodos considerados, e apenas um município, entre os quatorze São Domingos - reincide em todos os períodos. Em relação à área desmatada e ao valor das taxas, observam-se variações significativas de um período para o outro, inclusive para os municípios reincidentes. Outro fato que merece destaque é a participação dos municípios na quantidade de área desmatada. Dentre os 101 municípios responsáveis pelo desmatamento ocorrido no período de 2003 a 2004, apenas 20 foram responsáveis por 75\% do desmatamento. 


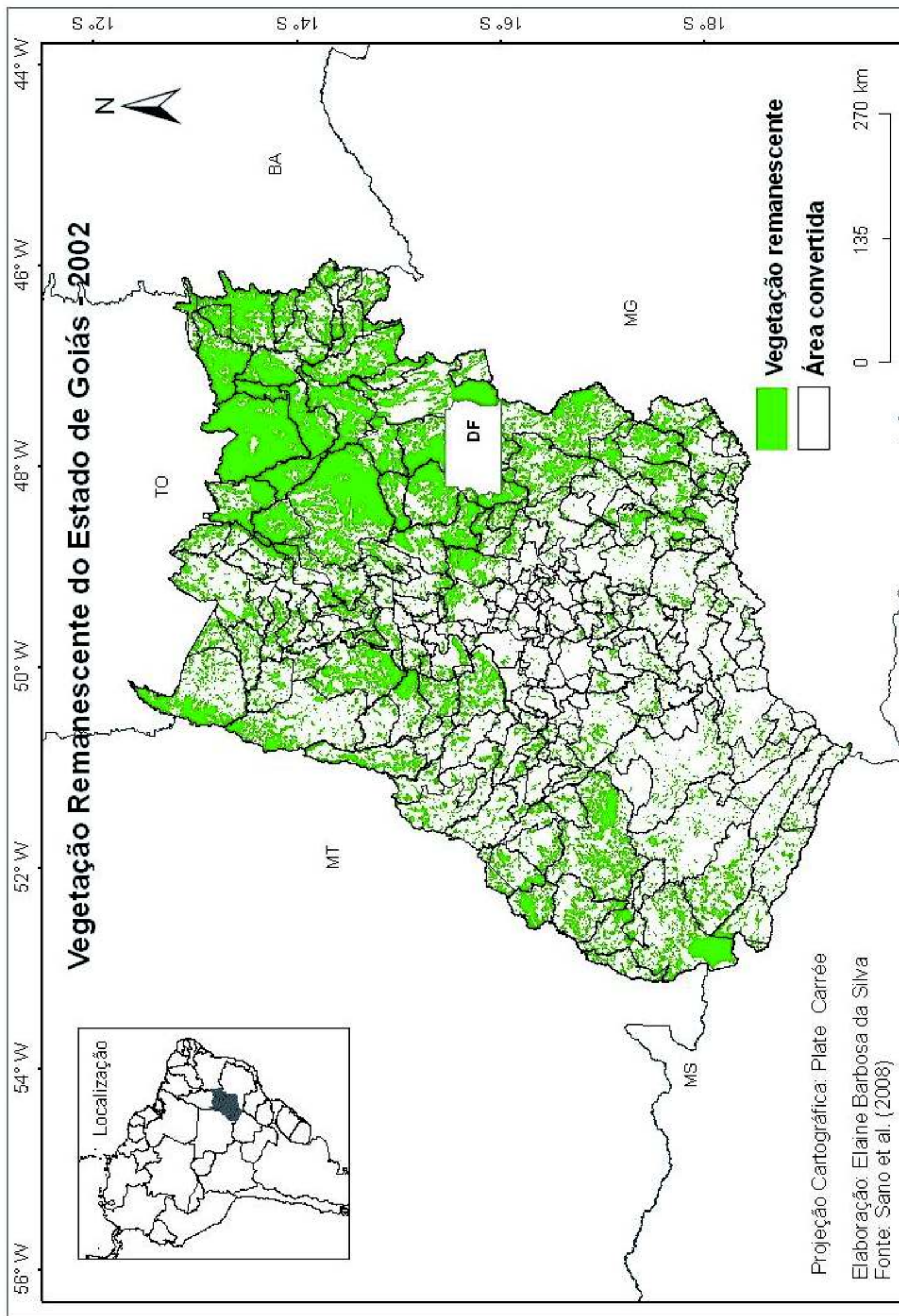

Figura 1 - Mapeamento da Distribuição da vegetação natural remanescente no estado de Goiás, conforme divisão municipal 


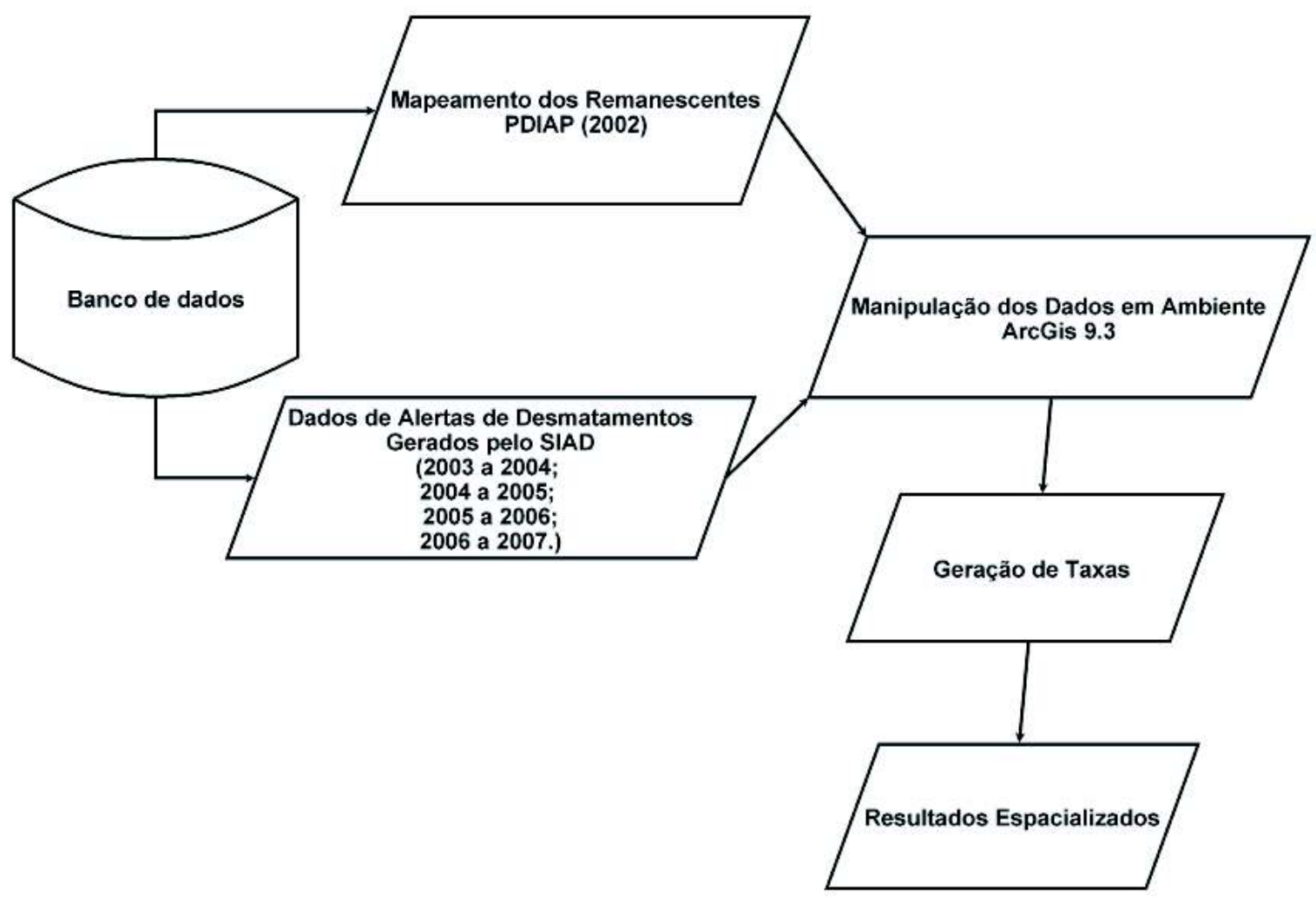

Figura 2 - Metodologia de obtenção das taxas de desmatamentos - em base municipal - para todo o Estado de Goiás.

No período de 2004 a 2005 ocorreu desmatamento em 62 municípios, sendo $75 \%$ do total desmatado concentraram-se em apenas 14 municípios. Quanto ao período de 2005 a 2006, foram detectados desmatamentos em 67 municípios, dos quais, 16 são responsáveis por $75 \%$ de toda a área desmatada. Já no período de 2006 a 2007, houve desmatamento em 48 municípios, 12 deles concentrando $75 \%$ da área desmatada. Em geral, pode-se dizer que $75 \%$ dos desmatamentos ocorridos nestes períodos concentraram-se em $25 \%$ dos municípios goianos.

É interessante observar que a distribuição das taxas de desmatamentos, tanto para o período total, quanto para o período de 2003 a 2004, é bastante ampla, com valores médios em torno de 0,6\%. Por outro lado, os períodos de 2004 a 2005, 2005 a 2006 e 2006 a 2007 apresentam taxas médias menores e menos concentradas espacialmente (i.e. bem distribuídas entre os municípios goianos) (figura 4).

Todas estas variações revelam a dificuldade em se determinar taxas de desmatamento considerando apenas um período de análise. As inconsistências dos padrões espaciais e temporais comprometem previsões de cenários futuros quando se toma um único período e o generaliza para outros. Alternativamente, ao considerar-se um período maior, no caso 2003 a 2007, percebe-se de forma mais clara as tendências de estabelecimento de padrões espaciais e temporais.

A espacialização das taxas (figura 3) revela situações distintas quanto à ocupação passada e atual do Cerrado goiano. Conforme mostra o mapa de remanescentes (figura 1), a região Sudeste, que apresenta uma ocupação consolidada, apresenta taxas de desmatamentos pouco expressivas. Por outro lado, as regiões Norte, Nordeste (corredor Paranã-Pireneus), Noroeste (Alto Araguaia) e Sudoeste ainda apresentam considerável cobertura de remanescente e, portanto, maiores desmatamentos em curso. 


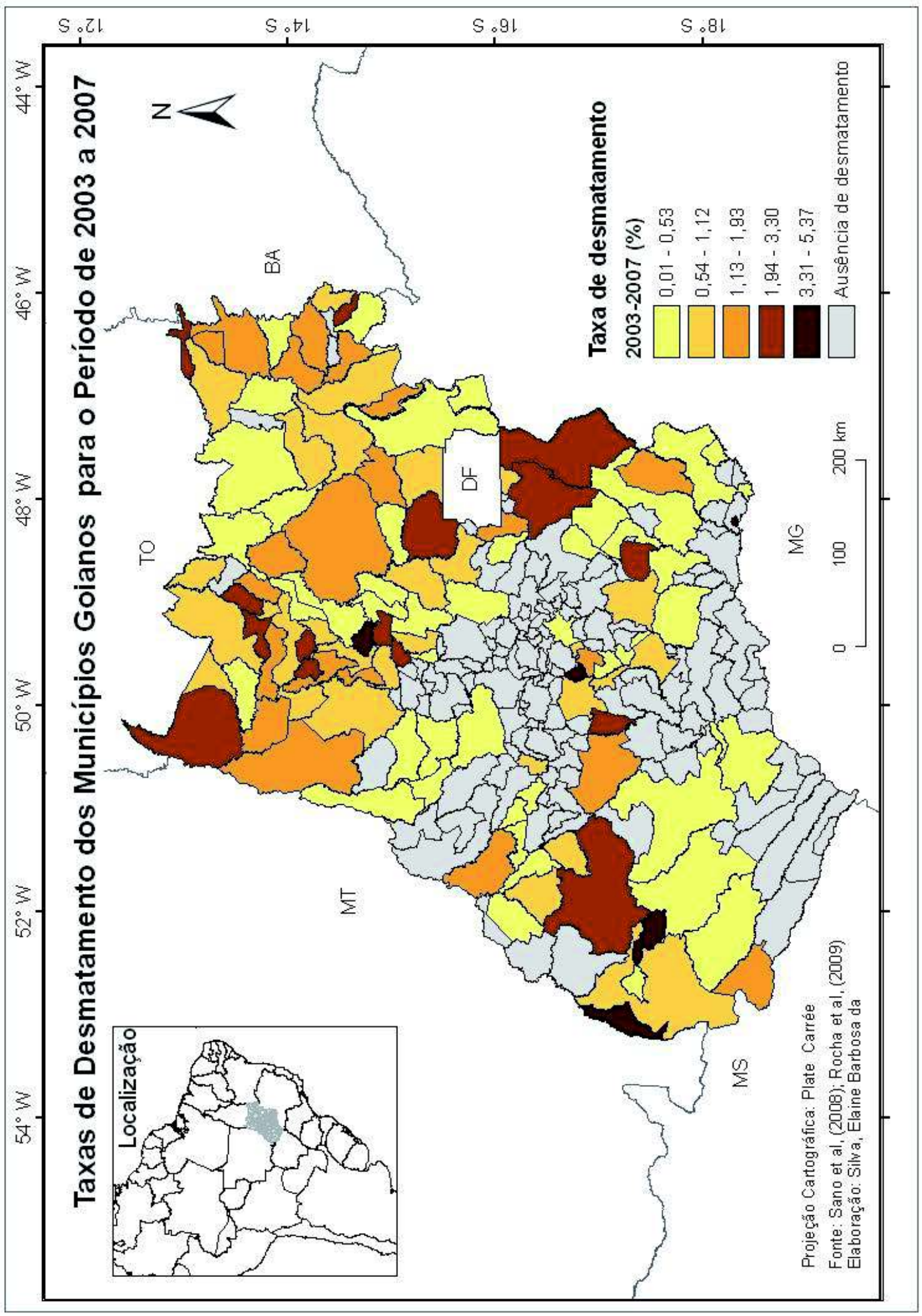

Figura 3 - Espacialização das taxas de desmatamentos no período de 2003 a 2007, conforme os 246 municípios do estado de Goiás. 
Tabela 1 - Municípios responsáveis por 75\% do desmatamento em Goiás - 2003-2004 / 2004-2005.

\begin{tabular}{lrr|l|l|l}
\hline \multicolumn{4}{c|}{ Desmatamento (2003 a 2004) } & \multicolumn{3}{c}{ Desmatamento (2004 a 2005) } \\
\hline \multicolumn{1}{c}{ Municípios } & Área (ha) & Taxa & \multicolumn{1}{c}{ Municípios } & Área (ha) & Taxa \\
\hline Niquelândia & $9.123,49$ & 1,31 & São Miguel do Araguaia & $3.734,86$ & 1,45 \\
Caiapônia & $8.168,77$ & 2,19 & Crixás & $1.242,84$ & 0,49 \\
Cristalina & $7.002,53$ & 2,26 & Niquelândia & $1.073,87$ & 0,16 \\
Padre Bernardo & $4.780,22$ & 2,45 & São Domingos & 988,68 & 0,41 \\
Luziânia & $3.519,62$ & 1,86 & Porangatu & 876,15 & 0,58 \\
São João D’Aliança & $2.375,71$ & 0,94 & Planaltina & 557,83 & 0,30 \\
Cavalcante & $2.177,03$ & 0,33 & Mundo Novo & 437,04 & 0,73 \\
São Domingos & $1.907,39$ & 0,78 & Mineiros & 378,45 & 0,10 \\
Mineiros & $1.758,72$ & 0,46 & Montes Claros de Goiás & 378,00 & 0,72 \\
Campinaçu & $1.576,05$ & 1,02 & Caiapônia & 350,02 & 0,10 \\
Santa Rita do Araguaia & $1.504,94$ & 3,16 & São João D’Aliança & 315,30 & 0,13 \\
Alto Paraíso de Goiás & $1.501,25$ & 0,69 & Amaralina & 292,30 & 0,50 \\
Água Fria de Goiás & $1.491,79$ & 1,11 & Alto Horizonte & 275,43 & 2,14 \\
Campo Alegre de Goiás & $1.397,66$ & 1,07 & Campinaçu & 263,40 & 0,17 \\
Monte Alegre de Goiás & $1.368,32$ & 0,52 & & & \\
laciara & $1.345,75$ & 1,69 & & & \\
Santo Antônio do & $1.257,83$ & 1,65 & & & \\
Descoberto & $1.244,02$ & 2,89 & & & \\
Santa Cruz de Goiás & $1.055,55$ & 1,70 & & & \\
Chapadão do Céu & 902,04 & 1,47 & & & \\
Paraná & & 1,47 & & & \\
Total/média & & & & & \\
\hline
\end{tabular}

Tabela 2 - Municípios responsáveis por 75\% do desmatamento em Goiás - 2005-2006 / 2006-2007.

\begin{tabular}{|c|c|c|c|c|c|}
\hline \multicolumn{3}{|c|}{ Desmatamento (2005 a 2006) } & \multicolumn{3}{|c|}{ Desmatamento (2006 a 2007) } \\
\hline Municípios & Área (ha) & Taxa & Municípios & Área (ha) & Taxa \\
\hline Cavalcante & $1.122,55$ & 0,17 & Nova Crixás & $1.496,76$ & 0,71 \\
\hline Posse & 774,52 & 0,84 & Crixás & 975,62 & 0,39 \\
\hline Planaltina & 693,04 & 0,38 & São Miguel do Araguaia & 923,93 & 0,37 \\
\hline São Miguel do Araguaia & 663,96 & 0,26 & Santa Rita do Araguaia & 896,24 & 1,94 \\
\hline Niquelândia & 590,22 & 0,09 & Monte Alegre de Goiás & 656,20 & 0,25 \\
\hline Nova Crixás & 556,26 & 0,26 & Amaralina & 638,47 & 1,09 \\
\hline Flores de Goiás & 534,46 & 0,23 & São Domingos & 637,33 & 0,26 \\
\hline Sítio D’Abadia & 431,21 & 4,64 & Perolândia & 559,42 & 3,70 \\
\hline São Domingos & 391,76 & 0,16 & Formosa & 539,61 & 0,18 \\
\hline Luziânia & 335,89 & 0,18 & Novo Planalto & 432,28 & 0,87 \\
\hline Campo Alegre de Goiás & 335,79 & 0,26 & Vila Boa & 327,51 & 0,60 \\
\hline Campos Belos & 247,11 & 0,55 & Mundo Novo & 258,47 & 0,44 \\
\hline Vila Propício & 231,98 & 0,25 & & & \\
\hline Mundo Novo & 224,55 & 0,38 & & & \\
\hline Alvorada do Norte & 197,91 & 0,30 & & & \\
\hline Mutunópolis & 194,31 & 1,08 & & & \\
\hline Total/média & $7.525,52$ & 0,63 & & $8.341,84$ & 0,90 \\
\hline
\end{tabular}

Nota: Nas tabelas 1 e 2 os municípios em negrito apresentaram reincidência de alertas de desmatamento nos quatro períodos interanuais considerados.

Embora as taxas, em geral, sejam relativamente baixas, estas são preocupantes, haja vista que $64 \%$ da cobertura nativa em Goiás já foram convertidas em pastagem, agricultura e outras formas de uso (SANO et al., 2008, p. 104). Quanto aos remanescentes, Ferreira et al. (2008, p. 171) constataram que 210 dos 246 municípios goianos já apresentam área convertida superior à área de remanescentes (Figura 5). 


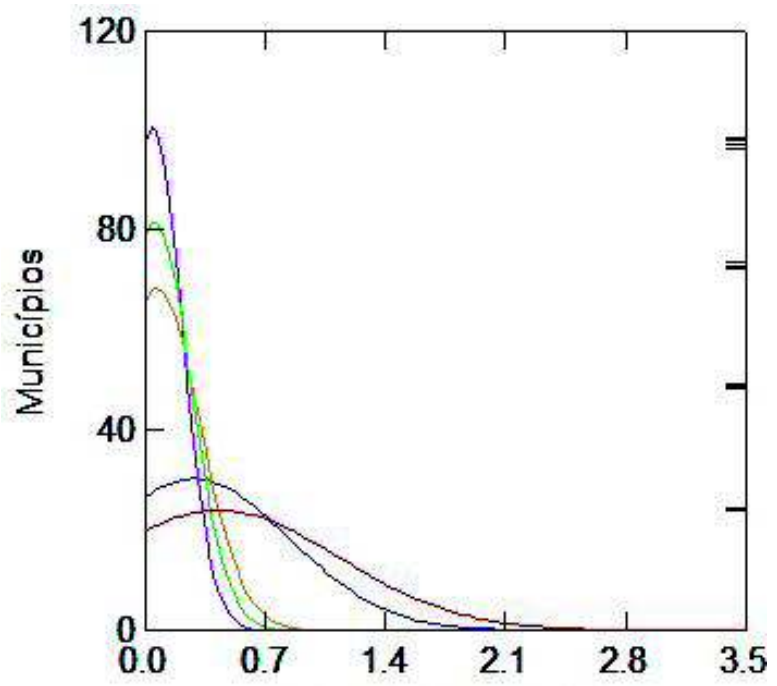

Figura 4 - Distribuição anual das taxas de desmatamento em municípios goianos - 2003 a 2007.

Como se pode observar no mapa da figura 6, os padrões espaciais das taxas de desmatamento entre 2003 e 2007 (figura 3) são coerentes com a distribuição da produção agrícola e pecuária para o mesmo período. De fato, o mapa de taxas de desmatamentos no Cerrado goiano entre 2003 e 2007 (figura 3) é, grosso modo, a junção dos mapas de criação de bovinos e de produção de grãos. Embora não seja possível espacializar a produção de carvão, tendo em vista que esta exploração, em grande parte, ocorre de forma clandestina, ela concentra-se no nordeste do Estado (AGMA, 2007), complementando, portanto, o mapa de espacialização de taxas de desmatamento.

A pecuária ocorre em toda a área do estado e está concentrada na mancha de ocorrência da soja, do milho e algodão, sobretudo na porção sudoeste do estado e em todo o oeste goiano. A produção de grãos, por sua vez, ocorre tanto nas áreas mais desmatadas - no limite entre o sudeste e o sudoeste do estado - quanto em áreas com maiores taxas de remanescentes, a exemplo do norte do Distrito Federal.

Em particular, o cultivo da soja forma uma mancha em formato de " $\mathrm{L}$ " invertido, a qual condiz com a localização das médias e altas taxas de conversão de remanescentes no sul e leste goianos (figura 5). O milho é a principal cultura de rotação associada à soja, motivo pelo qual tem a mesma distribuição espacial. É provável, portanto, que a soja e o milho estejam se expandindo por áreas recém-desmatadas.

O cultivo do algodão também apresenta distribuição espacial semelhante à da soja e do milho. Todas essas são culturas que predominam em áreas planas. Assim, é também possível que o algodão esteja em processo de avanço em áreas recém-desmatadas.

A produção de arroz, assim como a pecuária, mostra-se dispersa, lembrando antigas vocações do estado, datadas do século XIX (ESTEVAM, 1998, p. 85; DEUS, 2003, p. 244), e que persistem. Além da dispersão pelo estado, este grão está concentrado na zona de produção dos demais grãos; alastra-se, porém, até o nordeste do estado, a exemplo do que acontece com o feijão, que também se dispersa e encontra-se presente na mancha de produção de grãos. A produção de sorgo, a exemplo da soja e do algodão, está concentrada na porção sul do estado e apresenta grande crescimento de produção (figura 6).

O cultivo da cana-de-açúcar, ao contrário, está ocupando, sobretudo, áreas onde a conversão de remanescentes já cessou. A atividade sucroalcooleira desenvolveu-se fortemente na década de 1980 - no início do Proálcool - e consolidou-se no Centro-Sul do Estado. Por outro lado, nas duas últimas décadas outras culturas passaram a competir com a cana e ocuparam boa parte das terras planas do Sudeste e Sudoeste do Estado. Assim, mesmo resistindo no Centro-Sul goiano, a expansão da cana nos últimos anos encontrou dificuldades de ocupar áreas do Sudeste e Sudoeste e, por isso, 


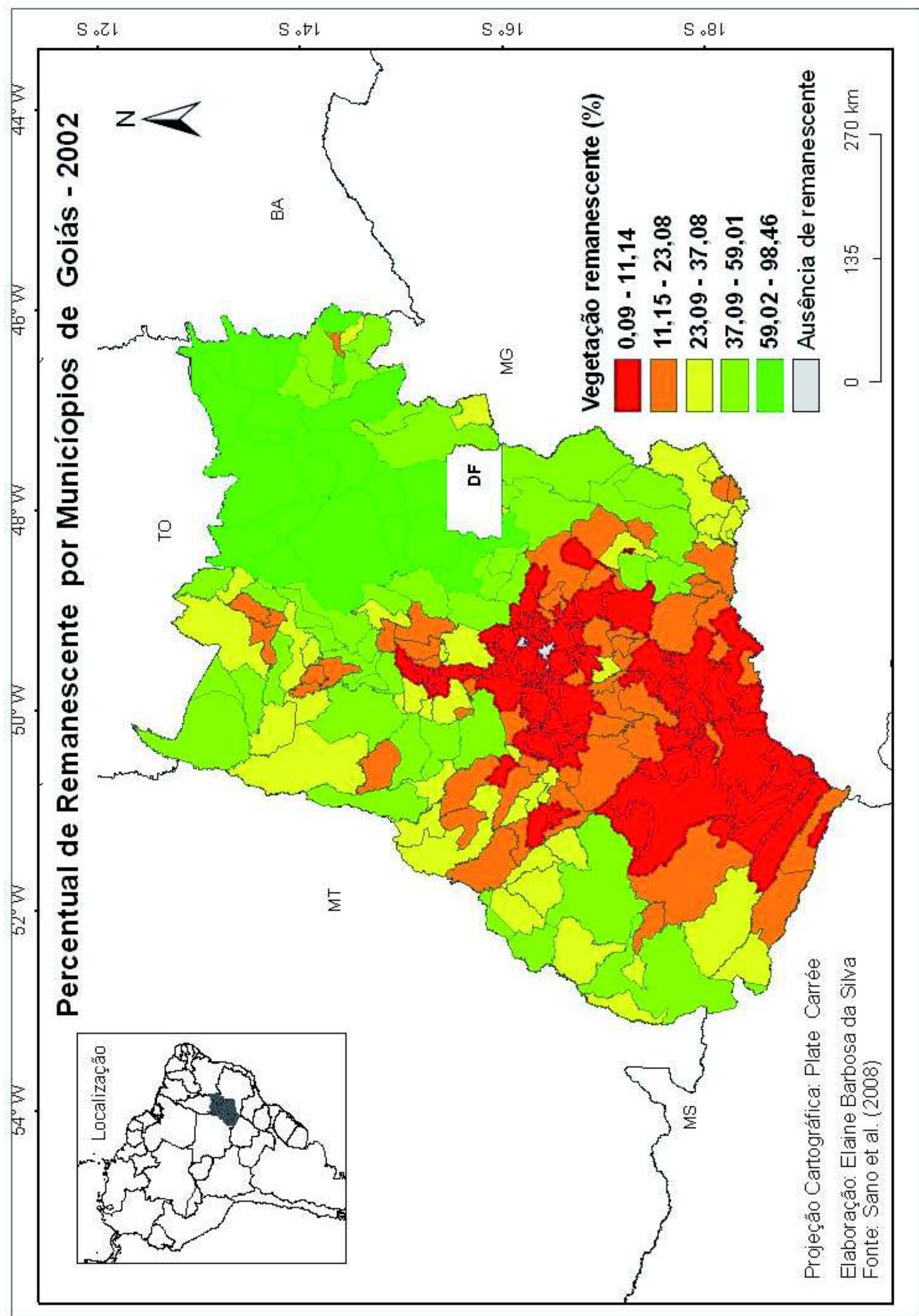

Figura 5 - Percentual de vegetação remanescente (2002) nos 246 municípios do estado de Goiás 


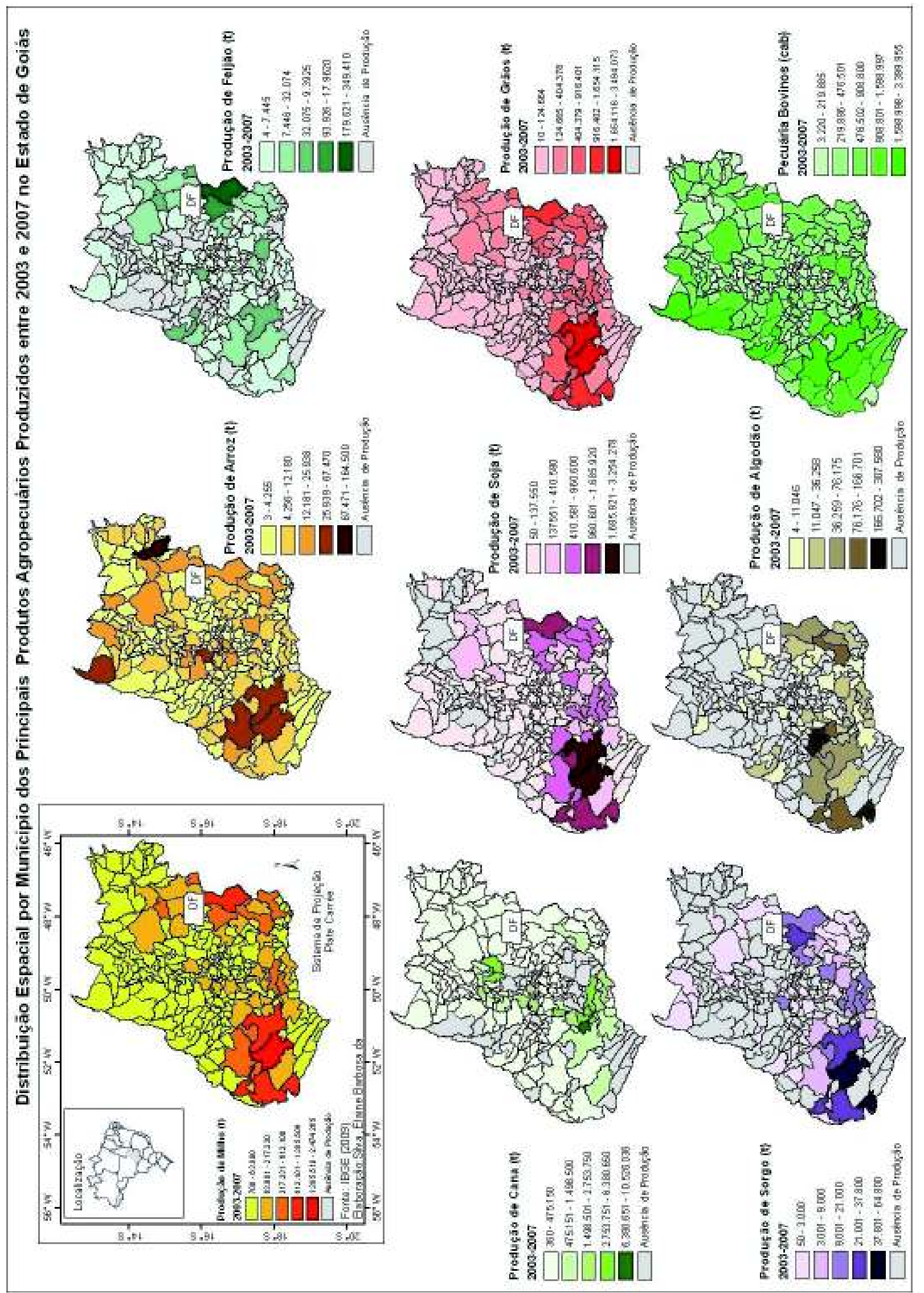

Figura 6 - Espacialização da produção agropecuária goiana por municípios, distribuída para o período de 2003 a 2007. 
buscou o Centro-Norte do Estado, que ainda não contava com expressiva produção sucroalcooleira.

Nessa nova zona de expansão, onde a conversão de remanescentes praticamente já cessou, a infra-estrutura e a proximidade do mercado consumidor (eixo Goiânia-Anápolis-Brasília) pode ter exercido grande influência na consolidação dessa produção. Note-se que, apesar dessa cultura não estar desmatando diretamente na maioria dos empreendimentos implantados no Centro-Norte, é bem provável que esteja ocorrendo substituição de culturas pela cana e que, em seu deslocamento, essas culturas estejam ocupando novas áreas e provocando um intenso desmatamento. Em fato, dados do Projeto Canasat/INPE para os períodos de 2005-2006, 2006-2007 e 2007-2008 mostram que a área de cana-de-açúcar em Goiás passou de 215.950 ha em 2005 para 328.291 ha em 2007, aumentando aproximadamente 52\% (INPE, 2007).

De todas as regiões onde há conversão de remanescentes, as mais preocupantes são as regiões Noroeste e Nordeste do estado. Como visto, a região Noroeste tem na expansão da criação de bovinos o principal propulsor da conversão de remanescentes, ainda que, provavelmente, produza muito carvão vegetal. Por sua vez, a região Nordeste, que conta com a maior reserva de Cerrado em Goiás, está se consolidando como área produtora de carvão vegetal (MARTINS JÚNIOR e CHAVES, 2008, p. 190).

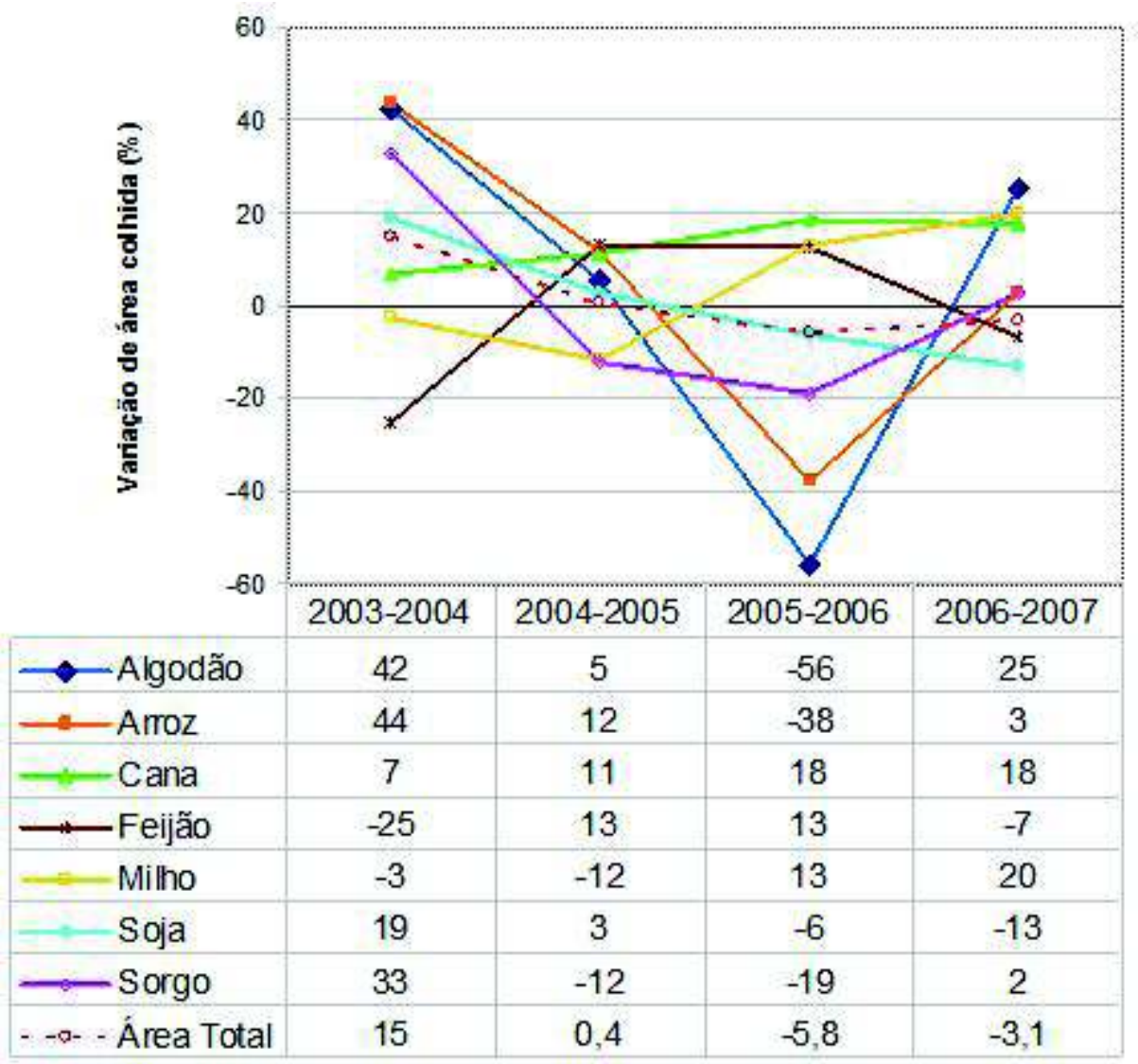

Figura 7 - Variação (\%) da área colhida por período anual, entre 2003 e 2007. Fonte: IBGE (2008)

Além da relação espacial entre a distribuição das taxas de desmatamento e produção agropecuária, verificou-se também a evolução da área plantada dos principais produtos agrícolas para o mesmo período. A tabela 3 e a figura 7 mostram, respectivamente, a evolução da área colhida das principais culturas no Estado e a variação da área colhida em cada período.

Conforme mostram a tabela 3 e a figura 6, a área de produção de grãos sofreu alteração anualmente, ora crescente, ora decrescente. Até mesmo a soja, que é responsável pela maior parte dos grãos produzidos, apresentou pequena oscilação durante o período total analisado. Quando 
se comparam as variações da área colhida e das taxas de desmatamento para um mesmo período, verifica-se certa semelhança de comportamento.

\begin{tabular}{|c|c|c|c|c|c|c|c|c|}
\hline \multirow{3}{*}{ Período } & \multicolumn{8}{|c|}{ Área colhida } \\
\hline & \multirow[b]{2}{*}{ Total } & \multicolumn{7}{|c|}{ Culturas } \\
\hline & & Algodão & Arroz & Cana & Feijão & Milho & Soja & Sorgo \\
\hline 2003 & 3.648 .216 & 99.347 & 114.894 & 164.861 & 139.852 & 716.047 & 2.176 .720 & 236.495 \\
\hline 2004 & 4.189 .407 & 141.555 & 165.427 & 176.328 & 104.422 & 696.324 & 2.591 .084 & 314.267 \\
\hline 2005 & 4.203 .056 & 149.114 & 184.950 & 196.596 & 118.242 & 614.709 & 2.663 .380 & 276.065 \\
\hline 2006 & 3.958 .004 & 66.033 & 114.875 & 232.577 & 133.358 & 695.127 & 2.492 .760 & 223.274 \\
\hline 2007 & 3.828 .541 & 82.807 & 117.897 & 273.870 & 124.452 & 832.224 & 2.168 .441 & 228.850 \\
\hline Total & 19.827 .224 & 538.856 & 698.043 & 1.044 .232 & 620.326 & 3.554 .431 & 12.092 .385 & 1.278 .951 \\
\hline
\end{tabular}

Tabela 3 - Evolução da área colhida das principais culturas produzidas no estado de Goiás, em hectares 2003-2007 Fonte: IBGE (2008)

Entre 2003 e 2004 ocorreram as maiores taxas de desmatamento de todo o período. Embora a área colhida dos principais grãos também tenha sido grande, o desmatamento ocorrido nesse período pode estar mais relacionado com o período seguinte - 2004 a 2005 -, tendo em vista que a agricultura demora certo tempo para que uma área desmatada venha a produzir determinado produto (FERREIRA et al., 2009, p. 121). De fato, a produção desse período subseqüente, obteve um incremento de $0,4 \%$. Chama também a atenção o fato destas essas taxas ocorrerem nos mesmos municípios onde há plantio de soja - que tem a maior área colhida -, arroz, feijão e nos municípios do Norte goiano, os quais, apesar da baixa produção, desmatam grandes áreas, sobretudo para a extração de carvão vegetal.

Para os demais períodos ocorreram as seguintes situações: queda de taxas de desmatamento de 2004 a 2005; alta nas taxas de 2005 a 2006; e significativa queda de 2006 a 2007. A redução das taxas no período de 2004-2005 coincide com a queda de área plantada no período de 2005 a 2006. Por outro lado, as altas taxas do período de 2005 a 2006 podem estar relacionadas com o leve incremento da área colhida no período subseqüente, de 2006 a 2007.

É interessante observar que a crescente produção de cana ocorreu em áreas onde raramente ocorreram desmatamentos, o que reforça a hipótese da expansão da cana sobre áreas de uso agropecuário consolidado.

\section{CONSIDERAÇÕES FINAIS}

Este estudo, com enfoque nos municípios goianos demonstrou que as taxas de desmatamentos anuais, ainda que sujeitas à variações significativas, tanto no seu contexto espacial, quanto temporal, possibilitam, juntamente com o histórico de ocupação do solo e espacialização de dados censitários, maior compreensão da ocupação atual, bem como de tendências e possíveis cenários futuros.

Por outro lado, e embora seja comum a utilização de taxas de desmatamento para a previsão de cenários e estabelecimentos de padrões, percebe-se que as variações anuais podem estar relacionadas a diversos fatores (políticos, econômicos, sociais e ambientais). Isto implica considerar que qualquer alteração em um destes fatores pode afetar diretamente os padrões espaciais e temporais de desmatamento. De fato, o uso de taxas deve sempre ser acompanhado de dados e considerações que auxiliem na compreensão da realidade. A dinâmica da produção agropecuária, como se mostrou aqui, explica, apenas em parte, a ocorrência do desmatamento no estado. Assim, o monitoramento anual - ou até mesmo à intervalos menores - da vegetação remanescente, associado à análise de diferentes fatores intervenientes - políticos, econômicos, sociais, etc. -, ao possibilitarem uma melhor definição de tendências e cenários, se tornam imprescindíveis à efetiva gestão territorial e ambiental do estado, ainda objeto de importante expansão agropecuária, em particular da cana-de-açúcar. 


\section{AGRADECIMENTOS}

Este trabalho foi desenvolvido no âmbito da parceria entre o Laboratório de Processamento de Imagens e Geoprocessamento (LAPIG - UFG), a Conservação Internacional (CI) e a The Nature Conservancy (TNC), que teve por objetivo a análise dos padrões espaciais e temporais dos desmatamentos no bioma Cerrado. Da mesma forma, os autores reconhecem e agradecem o apoio da Fundação de Amparo à Pesquisa do Estado de Goiás. A primeira autora foi bolsista de mestrado da CAPES e o segundo autor é bolsista produtividade em pesquisa (1C) do Conselho Nacional de Desenvolvimento Científico e Tecnológico (CNPq).

\section{REFERÊNCIA BIBLIOGRÁFICA}

AGMA. Agência Ambiental de Goiás. Desmatamento: trabalho inédito garante proteção ao Cerrado. Disponível em: <http://www3.agenciaambiental.go.gov.br/site/comunicacao/noticia_record_todas. php?d=332>. Acesso em: 17 mar. 2007.

BRASIL. Ministério do Meio Ambiente. Projeto Monitoramento do Desmatamento dos Biomas Brasileiros por Satélite. Disponível em: <http://siscom.ibama.gov.br/monitorabiomas/>. Acesso em: 14 nov. 2009. CONSERVAÇÃO INTERNACIONAL. Hotspot Revisatados. 2005. Disponível em: <http://www.conservation.org.br/publicacoes/files/HotspotsRevisitados.pdf > Acesso em: 12mai. 2008.

DIAS, Braulio Ferreira de Souza. Conservação da natureza. In: PINTO. Maria Novaes. (Org). Cerrado: caracterização, ocupação e perspectivas. 2. ed. Brasília-DF: Editora Universidade de Brasília, 1994. cap. 21. DEUS, João Batista de. O Sudeste goiano e a desconcentração industrial. Brasília: Ministério da Integração Nacional; Goiânia: UFG, 2003. 242 p.

ESTEVAM, Luis. O tempo da transformação - estrutura e dinâmica da formação econômica de Goiás. Goiânia: ed. do autor, 1998. 275 p.

FERREIRA JÚNIOR, Laerte Guimarães; FERREIRA, Manuel Eduardo; ROCHA, Genival Fernandes; PONTES, Marlon Nemayer; FERREIRA, Nilson Clementino. Dinâmica agrícola e desmatamentos em áreas de cerrado: uma analise a partir de dados censitários e imagens de resolução moderada. Revista Brasileira de Cartografia, Brasil, n. 62, p. 117-127, fev. 2009.

FERREIRA, Manuel Eduardo; FERREIRA JÚNIOR, Laerte Guimarães; FERREIRA, Nilson Clementino. Cobertura Vegetal Remanescente em Goiás: Distribuição, Viabilidade Ecológica e Monitoramento. In: FERREIRA JÚNIOR, L. G. (Org). A encruzilhada socioambiental: biodiversidade, economia e sustentabilidade no Cerrado. Goiânia-GO: Editora. Universidade Federal de Goiás, 2008. p. 179-185.

FERREIRA, Nilson Clementino; FERREIRA JÚNIOR, Laerte Guimarães; HUETE, Alfredo R; FERREIRA, Manuel Eduardo. An operational deforestation mapping system using MODIS data and spatial context analysis. International Journal of Remote Sensing, Estados Unidos, v. 28, p. 47-62, jan. 2007.

IBGE. Levantamento Sistemático da Produção Agrícola. Disponível em: < http://www.ibge.gov.br/home/ estatistica/indicadores/agropecuaria/lspa/default.shtm>Acesso em: 10 dez. 2008.

INPE. Área de Cana Safra e Reforma na Região Centro-Sul. Disponível em: $<$ http://www.dsr.inpe.br/ mapdsr/intro.jsp> Acesso em: 12 out. 2007.

MACHADO, Ricardo B.; RAMOS NETO, Mário B.; PEREIRA, Paulo Gustavo P.; CALDAS, Eduardo F.; GONÇALVES, Demerval A.; SANTOS, Nazareno S.; TABOR, Karine; STEININGER, Marc. Estimativas de perda da área do Cerrado brasileiro. Brasília: Conservation International do Brasil, 2004. Disponível em: < http://www.conservation.org.br/arquivos/RelatDesmatamCerrado.pdf $>$. Acesso em: 01 out. 2007.

MARTINS JÚNIOR, Osmar Pires; CHAVES, Flávio Teodoro. Uso de Instrumentos Econômicos para a Conservação da Biodiversidade em Goiás: Implicações e Perspectivas. In: FERREIRA JÚNIOR, Laerte Guimarães. (Org). A encruzilhada socioambiental: biodiversidade, economia e sustentabilidade no Cerrado. Goiânia-GO: Editora. Universidade Federal de Goiás, 2008. p. 187-198.

MONTALVANI, José Eduardo; PEREIRA, Alfredo. Estimativas da Integridade da Cobertura Vegetal do Cerrado Através de Dados TM/Landsat. In: SIMPÓSIO BRASILEIRO DE SENSORIAMENTO REMOTO,

Mercator - volume 9, número 18, 2010: jan./abr. 
9. (SBSR), 1998, Santos. Anais eletrônicos... São José dos Campos: INPE, 1998. Disponível em: http:// marte.dpi.inpe.br/col/sid.inpe.br/deise/1999/02.11.10.57/doc/2_168p.pdf. Acesso em: 10 abr. 2008.

MOREIRA, Maria Luiza Ozório; FERREIRA, Nilson Clementino. Base de Dados Geográficos para Gestão Territorial e Ambiental do Estado de Goiás. In: FERREIRA JÚNIOR, Laerte Guimarães. (Org). A encruzilhada socioambiental: biodiversidade, economia e sustentabilidade no Cerrado. Goiânia-GO: Editora Universidade Federal de Goiás, 2008. p. 151-168.

MYERS, Norman; MITTERMEYER, Russell A; MITTERMEYER, Cristina G; FONSECA, Gustavo A. B. da; KENT, Jennifer. Biodiversity hotspots for conservantion priorites. Nature, Estados Unidos, vol. 403, p. 853-858, jan. 2000. Disponível em: $<$ http://www.cienciaviva.pt/divulgacao/cafe/World_biodiversity_hotspots.pdf.> Acesso em: 15 ago 2008.

RIBEIRO, Noeli Vicente; FERREIRA JÚNIOR, Laerte Guimarães; FERREIRA, Nilson Clementino. Expansão do Setor Sucroalcooleiro no Cerrado Goiano: Cenários Possíveis e Desejados. In: IX SIMPÓSIO NACIONAL DO CERRADO E II SIMPÓSIO INTERNACIONAL DE SAVANAS TROPICAIS. Anais... Brasília: Embrapa, 2008. 1 CD-ROM.

ROCHA, Genival Fernandes; FERREIRA JÚNIOR, Laerte Guimarães; FERREIRA, Nilson Clementino; FERREIRA, Manuel Eduardo; SILVA, Gabriela Nogueira Ferreira da. Distribuição espacial dos dados de alertas de desmatamentos do bioma Cerrado para o período 2003-2007. In: SIMPÓSIO BRASILEIRO DE SENSORIAMENTO REMOTO, 14. (SBSR), 2009, Natal. Anais eletrônicos... São José dos Campos: INPE, 2009. Disponível em: < http://urlib.net/dpi.inpe.br/sbsr@80/2008/11.14.23.13 >. Acesso em: 07 jun. 2009. SANO, Edson Eyji; DAMBRÓS, Luis Alberto; OLIVEIRA, Geraldo César; BRITES, Ricardo Seixas. Padrões de cobertura de solos do Estado de Goiás. In: FERREIRA JÚNIOR, Laerte Guimarães (Org) A encruzilhada socioambiental: biodiversidade, economia e sustentabilidade no Cerrado. Goiânia-GO: Editora. Universidade Federal de Goiás, 2008. p. 91 - 106.

Trabalho enviado em março de 2010

Trabalho aceito em abril de 2010 